\title{
Histone deacetylase 1 and 2 differentially regulate apoptosis by opposing effects on extracellular signal-regulated kinase $1 / 2$
}

\author{
W-W Lei ${ }^{1}$, K-H Zhang ${ }^{1}$, X-C Pan ${ }^{1}$, D-M Wang ${ }^{1}$, Y Hu ${ }^{1}$, Y-N Yang ${ }^{1}$ and J-G Song ${ }^{*, 1}$
}

Histone deacetylases (HDACs) are epigenetic regulators that are important for the control of various pathophysiological events. We found that HDAC inhibitors completely abolished transforming growth factor- $\beta 1$ (TGF- $\beta 1$ )-induced apoptosis in AML-12 and primary mouse hepatocytes. Expression of a dominant-negative mutant of HDAC1 or downregulation of HDAC1 by RNAi both suppressed TGF- $\beta 1$-induced apoptosis. In addition, overexpression of HDAC1 enhanced TGF- $\beta 1$-induced apoptosis, and the rescue of HDAC1 expression in HDAC1 RNAi cells restored the apoptotic response of cells to TGF- $\beta 1$. These data indicate that HDAC1 functions as a proapoptotic factor in TGF- $\beta 1$-induced apoptosis. In contrast, downregulation of HDAC2 by RNAi increased spontaneous apoptosis and markedly enhanced TGF- $\beta 1$-induced apoptosis, suggesting that HDAC2 has a reciprocal role in controlling cell survival. Furthermore, inhibition of extracellular signal-regulated kinase $1 / 2$ (ERK1/2) by MEK1 inhibitor PD98059 or expression of a kinase-dead mutant of MEK1 restored the apoptotic response to TGF- $\beta 1$ in HDAC1 RNAi cells. Strikingly, HDAC2 RNAi caused an inhibition of ERK1/2, and the spontaneous apoptosis can be abolished by reactivation of ERK1/2. Taken together, our data demonstrate that HDAC1 and 2 reciprocally affect cell viability by differential regulation of ERK1/2; these observations provide insight into the roles and potential mechanisms of HDAC1 and 2 in apoptosis.

Cell Death and Disease (2010) 1, e44; doi:10.1038/cddis.2010.21; published online 20 May 2010

Subject Category: Cancer

This is an open-access article distributed under the terms of the Creative Commons Attribution License, which permits distribution and reproduction in any medium, provided the original author and source are credited. Creation of derivative works is permitted but the resulting work may be distributed only under the same or similar license to this one. This license does not permit commercial exploitation without specific permission.

Apoptosis is a highly controlled process that has been implicated in various physiological and pathological events. During apoptosis, cells shrink, chromatin becomes fragmented, the nucleus becomes condensed and/or fragmented. Disruption of the normal control of apoptosis has been linked with various pathological events. Transforming growth factor (TGF)- $\beta$ is a pleiotropic growth factor that positively or negatively regulates many biological events depending on cell status, cell type and environmental context. TGF- $\beta$ has been shown to be a strong inducer of apoptosis in primary rat hepatocytes, Hep-3B, HuH-7, FaO hepatoma cell lines and AML-12 murine hepatocytes. ${ }^{1-6}$ In addition, dysregulation of TGF- $\beta$-mediated apoptosis occurs in many diseases, such as fibrosis, autoimmunity, inflammation and tumorigenesis. ${ }^{7-9}$ Although tremendous progress has been made in exploring the regulatory effects of TGF- $\beta 1$-induced apoptosis, further studies are important for a better understanding of the underlying mechanisms.

Mitogen-activated protein kinase (MAPK) cascades are conserved signal-transduction pathways that respond sensitively to diverse extracellular stimuli in mediating cell proliferation, differentiation, migration, stress responses, inflammation and apoptosis. $^{10}$ Extracellular signal-regulated kinases $1 / 2$ (ERK1/2) are important survival factors that have been shown to have significant roles during TGF- $\beta$-mediated biological events. ERK1/2 inactivation has been reported to enhance TGF- $\beta$-induced apoptosis and the suppression of proliferation, ${ }^{11-14}$ whereas ERK $1 / 2$ activation is involved in TGF- $\beta$-induced suppression of apoptosis and promotion of proliferation. ${ }^{15-17}$ ERK1/2 are also required for TGF- $\beta$ induced cell migration ${ }^{18-20}$ and the epithelial-to-mesenchymal transition. ${ }^{21,22}$ However, knowledge regarding the factors that control ERK1/2-mediated cell viability still remains limited.

Not only do histone deacetylases (HDACs) classically function as epigenetic regulators through histone deacetylation but they can also function on other proteins such as transcription factors to regulate gene transcription. HDACs control various biological events including cardiac development, skeletogenesis, cytoskeletal dynamics and the integrity of endothelium. ${ }^{23}$ There are 18 mammalian HDACs, which

\footnotetext{
${ }^{1}$ Laboratory of Molecular Cell Biology, Institute of Biochemistry and Cell Biology, Shanghai Institutes for Biological Sciences, Chinese Academy of Sciences, Shanghai 200031, China

*Corresponding author: J-G Song, Laboratory of Molecular Cell Biology, Institute of Biochemistry and Cell Biology, Shanghai Institutes for Biological Sciences, Chinese Academy of Sciences, 320 Yueyang Road, Shanghai 200031, China. Tel and Fax: + 8621549 21167; E-mail: jgsong @ sibs.ac.cn Keywords: apoptosis; HDAC1; HDAC2; TGF- $\beta 1$; ERK1/2; signalling

Abbreviations: HDAC, histone deacetylase; TGF- $\beta 1$, transforming growth factor- $\beta 1$; ERK1/2, extracellular signal-regulated kinase $1 / 2$; MEK1, MAPKK1, mitogenactivated protein kinase kinase 1; DN-HDAC1, dominant-negative HDAC1; KD-MEK1, kinase-dead MEK1; TSA, trichostatin A; NaBu, sodium butyrate; AO/EB, acridine orange/ethidium bromide; MDCK, Madin-Darby canine kidney; EGF, epithelial growth factor

Received 01.2.10; revised 26.3.10; accepted 01.4.10; Edited by P Salomoni
} 
are grouped into four classes. The class I HDACs include HDAC1, 2, 3 and 8 and are predominantly localised in the nucleus. HDAC1 and 2 are the two closest homologues, sharing the highest level of sequence identity. They heterodimerise and form complexes with other molecules to execute the same functions, such as the regulation of cardiac development. ${ }^{24}$ HDAC1 and 2 have also been shown to have different biological functions. During embryonic differentiation, HDAC1 is required for neuronal differentiation, whereas HDAC2 specifically inhibits astrocyte differentiation. ${ }^{25}$ There are also discrepancies between the reported roles of HDAC1 and 2 in apoptosis. Knockdown of HDAC1 but not 2 in U2OS osteosarcoma cells has been shown to induce apoptosis, ${ }^{26}$ whereas the knockdown of HDAC2 but not HDAC1 in HeLa cells results in apoptosis. ${ }^{27}$ However, there is no evidence regarding the roles of HDAC1 and 2 in controlling apoptosis in normal cells.

HDAC inhibitors are potent inducers of apoptosis in cancer cells. They suppress tumour growth and progression, induce the differentiation of transformed cells and inhibit tumour angiogenesis and invasion in vivo. ${ }^{28}$ Hence, HDAC inhibitors have been considered as potential drugs for cancer treatment. HDAC inhibitors are also well-studied for their selectivity, because they can induce the apoptosis of cancer cells but possess less toxicity towards non-cancer cells. ${ }^{29}$ Death receptor and mitochondrial death pathways have been shown to participate in HDAC inhibitor-induced apoptosis. ${ }^{30}$ However, very little is known about the biological effects of HDAC inhibitors on the viability of normal cells. In addition, most HDAC inhibitors inhibit HDACs non-selectively, so the roles of different HDACs cannot be identified using HDAC inhibitors alone.

In this study, we examined the roles of HDAC inhibitors, HDAC1 and 2, on TGF- $\beta 1$-induced apoptosis in mouse hepatocytes. We showed that HDAC inhibitors suppress TGF- $\beta 1$-induced apoptosis and demonstrated that HDAC1 and 2 had opposite roles in apoptosis. The study revealed that opposing regulation of ERK1/2 contributed to the opposite roles of HDAC1 and 2.

\section{Results}

HDAC inhibitors suppress TGF- $\beta 1$-induced apoptosis in hepatocytes. To investigate whether HDACs, which are major epigenetic regulators, are involved in the control of cell apoptosis, we examined the effects of three structurally unrelated HDAC inhibitors, trichostatin A (TSA), sodium butyrate $(\mathrm{NaBu})$ and $\mathrm{MS}-275$, on TGF- $\beta 1$-induced apoptosis in $\mathrm{AML}-12$ hepatocytes. AML-12 cell line was established from hepatocytes from the mouse transgenic for human TGF $-\alpha{ }^{31}$ These cells exhibit typical hepatocyte features, such as peroxisomes and bile canalicular-like structure and expressing high levels of serum and gap junction proteins. ${ }^{31}$ Most importantly, AML-12 cells are as sensitive as primary hepatocytes to the TGF- $\beta 1$, and results obtained from AML-12 cells are highly consistent with that from primary hepatocytes. TGF- $\beta 1$ treatment induces both apoptosis and epithelial-mesenchymal transition. ${ }^{32,33}$ As shown in Figure 1, HDAC inhibitors inhibited TGF- $\beta 1$-induced apoptosis, as determined by FACS (Figure 1a), acridine orange/ethidium bromide (AO/EB) staining assay (Figure 1b), caspase-3 activity (Figure 1c) and DNA fragmentation (Supplementary Figure $1 \mathrm{a}-\mathrm{c}$ ). Consistently, all three HDAC inhibitors also abolished TGF- $\beta 1$-induced apoptosis in primary mouse hepatocytes, as determined by FACS (Figure 1d), AO/EB staining (Figure 1e) and caspase-3 activity (Figure 1f). The above results suggest that HDACs have critical roles in TGF- $\beta 1$-induced apoptosis in hepatocytes. These results indicate that HDAC1 may be involved in TGF- $\beta 1$-induced apoptosis in hepatocytes. Because MS-275 is a relative HDAC1-selective inhibitor, whose $\mathrm{IC}_{50}$ value for $\mathrm{HDAC} 1^{34,35}$ is much lower than that for other HDACs, and there is an increase in the HDAC1 but not HDAC2 activity during TGF$\beta 1$-induced apoptosis in AML-12 (Supplementary Figure 2a) and primary hepatocytes (Supplementary Figure $2 b$ ), the effect of MS-275 may be linked with the inhibition of HDAC1 activity.

HDAC1 is required for TGF- $\beta 1$-induced apoptosis. Next we investigated the roles of HDAC1 in TGF- $\beta 1$-induced apoptosis. We constructed dominant-negative c-myc-tagged HDAC1 (DN-HDAC1) plasmids by substituting a conserved histidine (histidine 141) in the catalytic domain with an alanine. ${ }^{36,37}$ Stably transfected cell clones were obtained by transfection and were examined by immunoblotting (Supplementary Figure 3a). The results show that TGF- $\beta 1$ induced apoptosis was completely suppressed in DN-HDAC1 cells, as detected by FACS (Figure 2a) and $A O / E B$ staining (Figure $2 b$ ). To confirm the role of HDAC1, GFP-tagged wild-type HDAC1 or GFP empty vector plasmid was transfected into AML-12 cells and stable clones were selected by detecting GFP: The HDAC1-GFP fusion proteins were exclusively localised in the nucleus, compared with the diffuse distribution pattern of soluble GFP (Supplementary Figure 3b). Both GFP and HDAC1-GFP can also be detected by immunoblotting with GFP antibody (Supplementary Figure 3c). Compared with overexpression of GFP alone, overexpression of HDAC1-GFP significantly increased TGF- $\beta 1$-induced apoptosis (Figure $2 \mathrm{c}$ ). To further confirm the above results, we constructed two HDAC1 RNAi plasmids with different target sequences (iHDAC1-S1 and -S2). After transfection, stable cell clones were selected (Supplementary Figure 3d). As determined by FACS, TGF- $\beta 1$-induced apoptosis was significantly decreased in iHDAC1 cells (Figure $2 \mathrm{~d}$ ). The inhibition of TGF- $\beta 1$-induced apoptosis by HDAC1 RNAi was also identified by DNA fragmentation (Figure 2e) and AO/EB staining (Figure 2f) assays. In addition, reintroduction of RNAi-resistant human GFP-tagged HDAC1 back into iHDAC1 cells restored the TGF- $\beta 1$-induced apoptotic response (Figure $2 \mathrm{~g}$ ). These data demonstrate that HDAC1 is required for TGF- $\beta 1$-induced apoptosis in AML12 mouse heaptocytes.

HDAC2 is required for survival of AML-12 hepatocytes. To study the role of HDAC2 in TGF- $\beta 1$ induced apoptosis, HDAC2 RNAi plasmid (iHDAC2) was constructed and transfected into AML-12 cells. Several stable cell clones were selected (Supplementary Figure 3d). Surprisingly, downregulation of HDAC2 by 
a

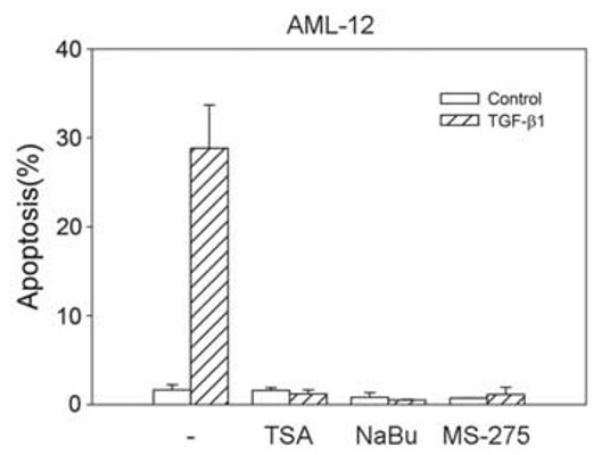

b

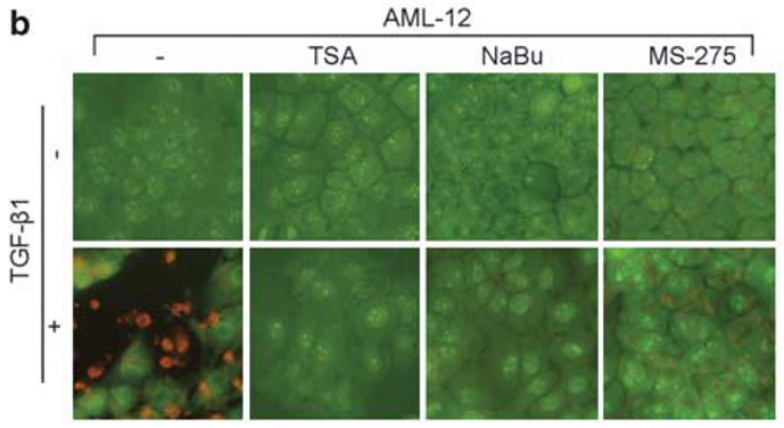

C

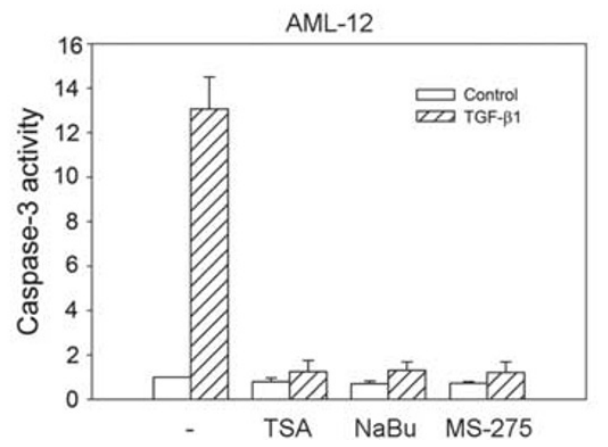

d

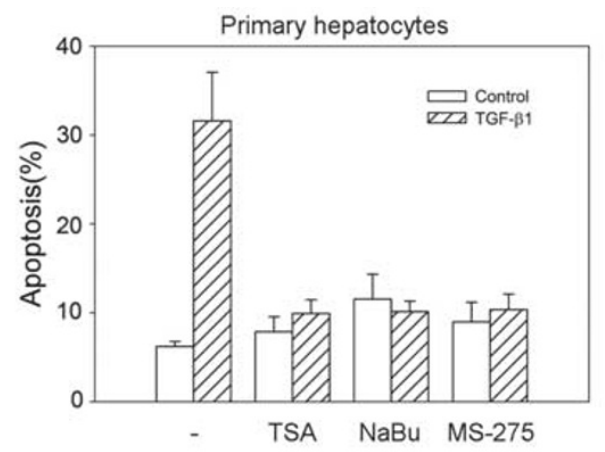

e

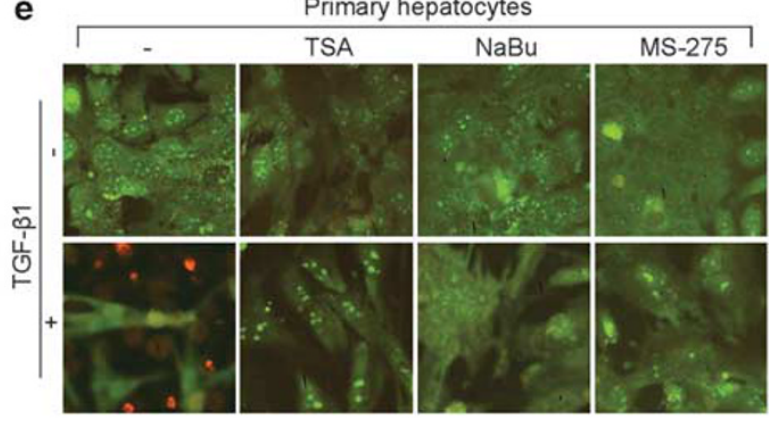

f

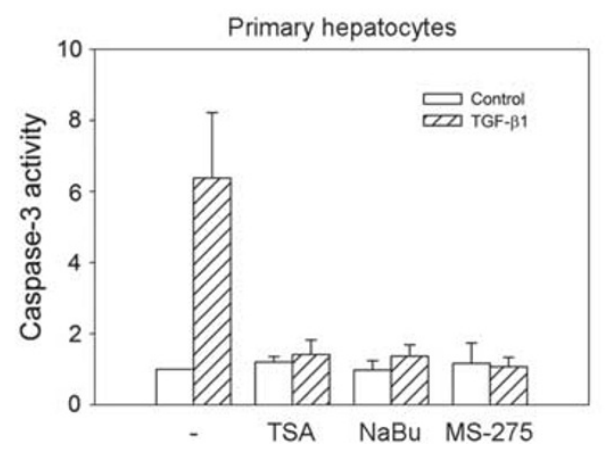

Figure 1 HDAC inhibitors block TGF- $\beta 1$-induced apoptosis. AML-12 cells and primary mouse hepatocytes were treated with TGF- $\beta 1$ in the presence of the HDAC inhibitors TSA, MS-275 or NaBu. The TGF- $\beta 1$ concentration and time for treatment were $5 \mathrm{ng} / \mathrm{ml}$ and $48 \mathrm{~h}$, unless otherwise indicated. The effects of inhibitors on TGF- $\beta 1$-induced apoptosis in AML-12 cells were examined by FACS (a), AO/EB staining (b) and caspase-3 activity (c). The effects of inhibitors on TGF- $\beta 1$-induced apoptosis in primary mouse hepatocytes were examined by FACS (d), AO/EB staining (e) and caspase-3 activity (f). Data are presented as means \pm S.D. from at least three independent experiments

HDAC2 RNAi caused spontaneous cell apoptosis, as determined by FACS (Figure 3a), DNA fragmentation (Figure $3 b$ ) and AO/EB staining (Figure 3c). In addition, downregulation of HDAC2 significantly increased the apoptotic response of cells to TGF- $\beta 1$ treatment (Figure $3 d-f)$. These results indicate that in contrast to HDAC1, HDAC2 has important part in the survival of AML-12 hepatocytes.

HDAC inhibitors abolish TGF- $\beta 1$-induced inhibition of ERK1/2 to suppress apoptosis. ERK1/2 is a well-known survival factor and its inactivation has been recently shown to increase the TGF- $\beta 1$-induced apoptosis. ${ }^{12}$ TGF- $\beta 1$ treatment inhibited ERK1/2 as shown by a decrease in the levels of phosphorylated ERK1/2 ( $p-E R K 1 / 2)$ in AML-12 cells and primary hepatocytes (Figure $4 \mathrm{a}$ ). Interestingly, TGF- $\beta 1$ did not inhibit ERK1/2 in MDCK (Madin-Darby canine kidney), 3T3-L1 and A549 cells (Supplementary Figure 4a), which corresponds to its inability to induce apoptosis in these cells (Supplementary Figure 4b). Thus, it suggests that inhibition of $\mathrm{p}$-ERK1/2 contributed to TGF- $\beta 1$-induced apoptosis. Moreover, TSA treatment activated ERK1/2 in AML-12 and primary hepatocytes in time- and dose-dependent manners (Figure 4b). Similar effect of $\mathrm{NaBu}$ and MS-275 was also observed in AML-12 cells (Supplementary Figure 5a and b). Consistent with these observations, TSA treatment partially but significantly reduced TGF- $\beta 1$-induced inhibition of ERK1/2 levels (Figure 4c). In the presence of PD98059, an inhibitor of mitogen-activated protein kinase kinase 1 (MAPKK1, MEK1), the basal level of activated ERK1/2 was significantly reduced, and more pronounced decrease was observed in the presence of both PD98059 and TGF- $\beta 1$ 


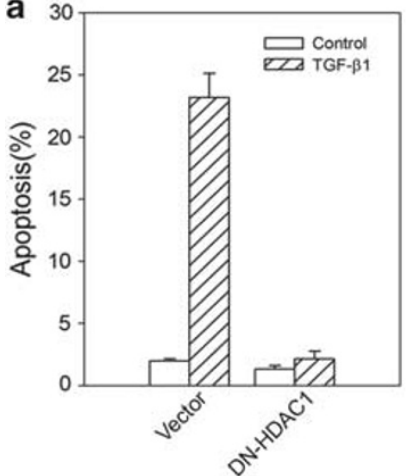

d

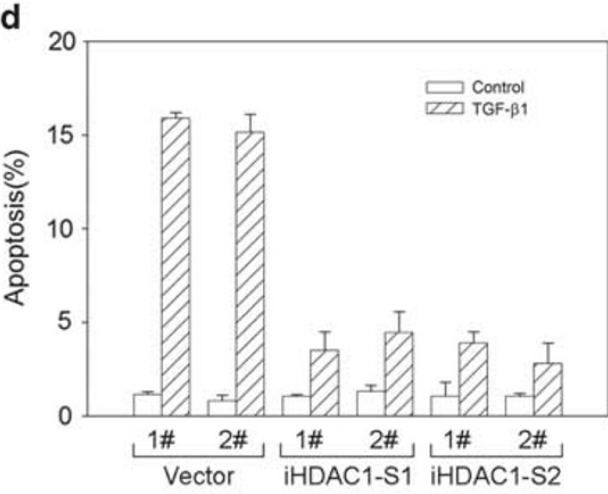

f

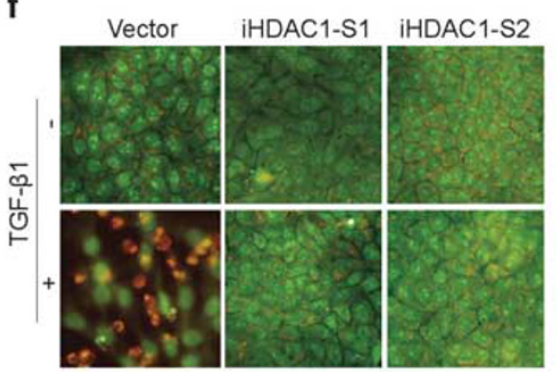

b
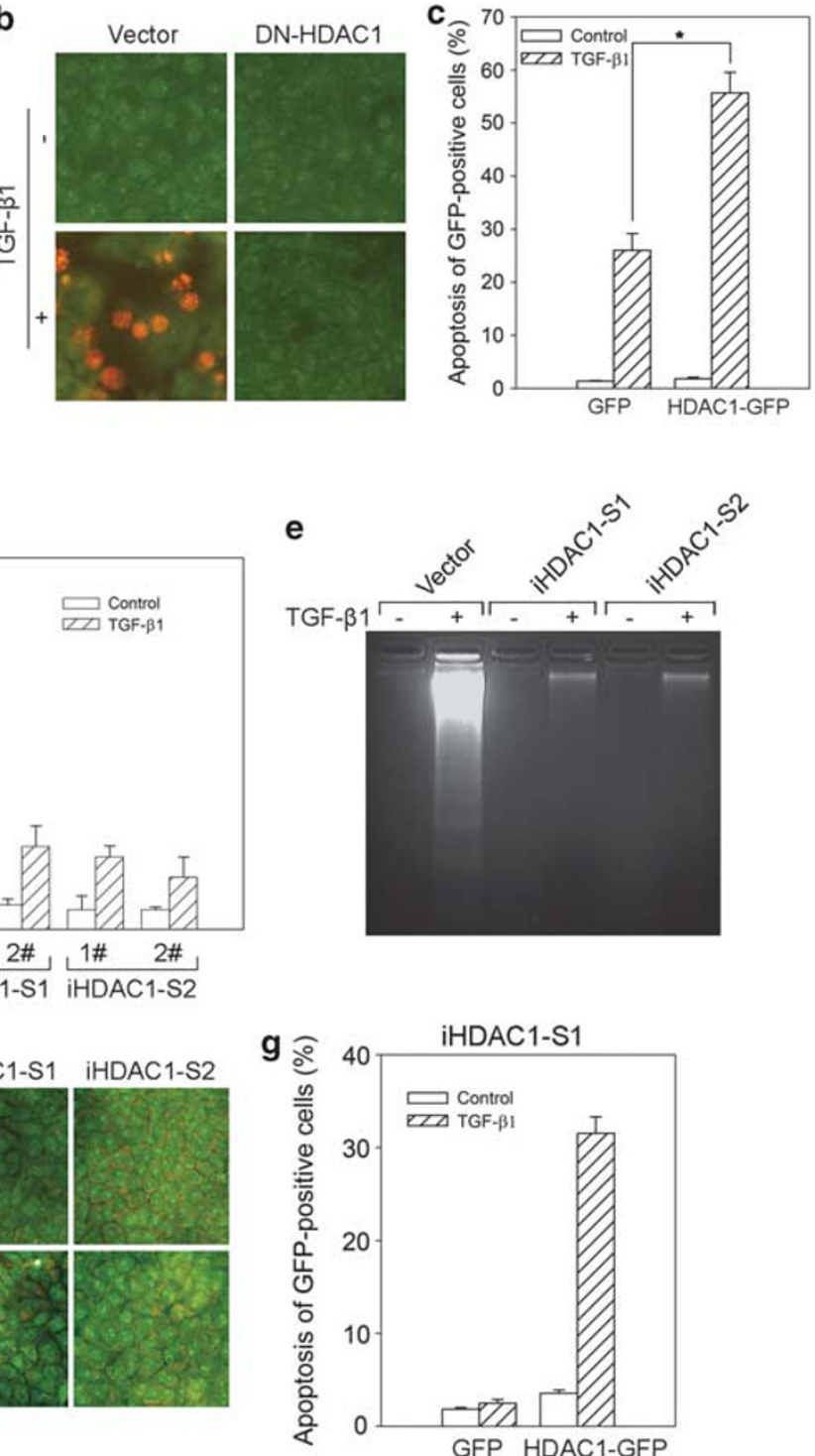

Figure 2 HDAC1 is required for TGF- $\beta 1$-induced apoptosis. TGF- $\beta 1$-induced apoptosis in DN-HDAC1 cells was examined by FACS (a) and AO/EB staining assays (b). TGF- $\beta 1$-induced apoptosis in GFP empty vector- and GFP-HDAC1-transfected cells (c), and in iHDAC1 cells was examined by FACS (d). Apoptosis in iHDAC1-S1-1\# and iHDAC1-S2-1\# clones in response to TGF- $\beta 1$ was examined by AO/EB staining (e) and DNA fragmentation assay (f). iHDAC1-S1-1\# cell clone was transfected with GFP-tagged HDAC1 or GFP vector. GFP staining and TGF- $\beta 1$-induced cell apoptosis were determined by FACS (g). Values represent means \pm S.D. of at least three independent experiments

(Figure 4d). Correspondingly, much stronger apoptosis was induced by TGF- $\beta 1$ and PD98059 used together (Figure $4 \mathrm{e}$ ). However, because TSA can fundamentally induce the ERK1/2 activation even in the presence of both PD98059 and TGF- $\beta 1$, apoptosis induced by TGF- $\beta 1$ and PD98059 used together was still markedly reduced by TSA in AML-12 and primary mouse hepatocytes (Figure 4e). These results suggest that ERK $1 / 2$ activation is required for HDAC inhibitor-mediated suppression of TGF- $\beta 1$-induced apoptosis in hepatocytes.

HDAC1 regulates apoptosis by inhibiting ERK1/2 phosphorylation. To determine whether the regulation of $\mathrm{ERK} 1 / 2$ is related to the role of HDAC1 in TGF- $\beta 1$-mediated apoptosis, we examined p-ERK1/2 levels in HDAC1 small interfering RNA-transfected cells. In iHDAC1 cells, as compared with empty vector-transfected cells, TGF- $\beta 1$ treatment cannot inhibit the ERK1/2 (Figure 5a). Furthermore, inhibition of ERK1/2 by PD98059 restored the apoptotic response of iHDAC1 cells to TGF- $\beta 1$ stimulation (Figure 5b), suggesting further that HDAC1 mediates TGF- $\beta 1$-induced apoptosis by inactivating ERK1/2. To confirm these results, AML-12 cells were transfected with the kinasedead form (K97A) of MEK1 (KD-MEK1). As a result, the $\mathrm{p}$-ERK1/2 levels in cells stably transfected with the HAtagged KD-MEK1 were significantly reduced (Supplementary Figure $6 \mathrm{a}$ ) and the apoptotic response of cells to TGF- $\beta 1$ was enhanced (Supplementary Figure 6b). Interestingly, TSA 

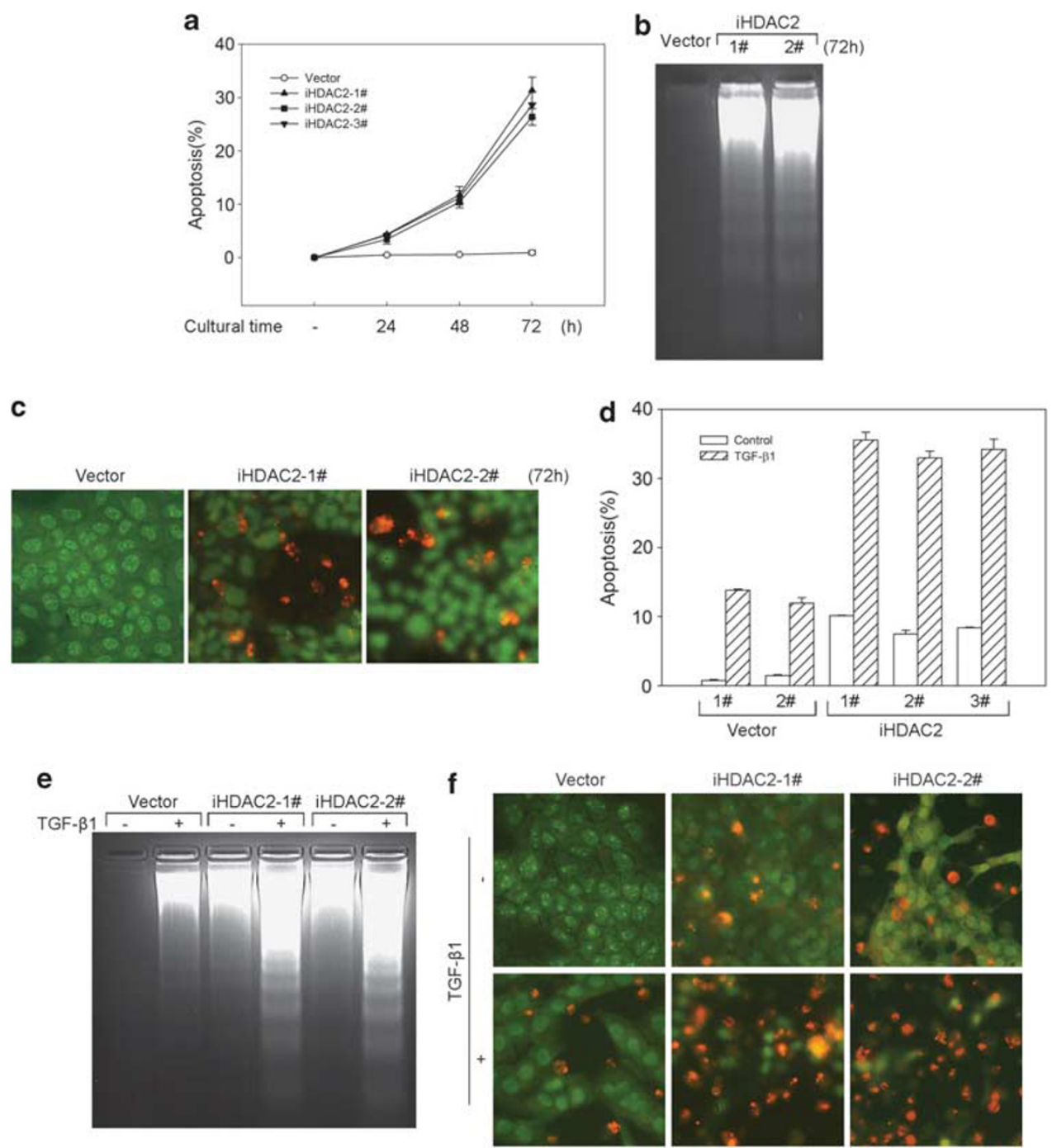

Figure 3 HDAC2 is important for cell survival. The empty vector- and iHDAC2-transfected AML-12 cells were cultured for the indicated times. Spontaneous cell apoptosis was determined by FACS (a), DNA fragmentation (b) and AO/EB staining (c). The empty vector and iHDAC2 cells were treated with TGF- $\beta 1$ for $48 \mathrm{~h}$, and then apoptosis was examined by FACS (d), DNA fragmentation (e) and AO/EB staining (f). Data are presented as means \pm S.D. from at least three independent experiments

treatment restored $\mathrm{p}-\mathrm{ERK} 1 / 2$ to background levels (Supplementary Figure $6 \mathrm{c}$ ) and also reduced TGF- $\beta$ induced apoptosis in KD-MEK1 cells (Supplementary Figure 6d). In addition, overexpression of GFP-tagged KD-MEK1 in iHDAC1 cells (Figure $5 \mathrm{c}$ ) restored the apoptotic response of these cells to TGF- $\beta 1$ (Figure $5 \mathrm{~d}$ ). These results further support that $p-E R K 1 / 2$ has a critical role in HDAC1mediated TGF- $\beta$-induced apoptosis in AML-12 mouse hepatocytes.

HDAC2 increases cell viability through activation of ERK1/2. Because HDAC2 downregulation increased apoptotic response to TGF- $\beta 1$ (Figure 3) and caused significant spontaneous apoptosis (Figure 3), HDAC2 appeared important for the survival of AML-12 hepatocytes. Indeed, ERK1/2 were significantly inhibited in iHDAC2 cells compared with control and iHDAC1 cells (Figure 6a). Treatment of cells with epithelial growth factor (EGF), which activated ERK1/2 in iHDAC2 cells (Figure 6b), reduced the spontaneous apoptosis (Figure 6c), indicating that ERK1/2 inhibition contributed at least in part the spontaneous apoptosis in iHDAC2 cells. In addition, TSA treatment also restored the levels of activated ERK $1 / 2$ levels in iHDAC2 cells (Figure 6d) and suppressed spontaneous apoptosis (Figure 6e). Inhibition of HDAC1 by MS-275 also activated ERK1/2 (Figure 6f) and inhibited apoptosis in iHDAC2 cells (Figure $6 \mathrm{~g}$ ), suggesting that HDAC1 functions as a proapoptotic factor by inhibiting ERK1/2 during spontaneous apoptosis in HDAC2-deficient cells.

\section{Discussion}

HDAC inhibitors have been widely used to investigate the roles and involvement of HDACs in various biological events. In this study, we showed that HDAC inhibitors powerfully suppress TGF- $\beta 1$-induced apoptosis in mouse hepatocytes. 
a

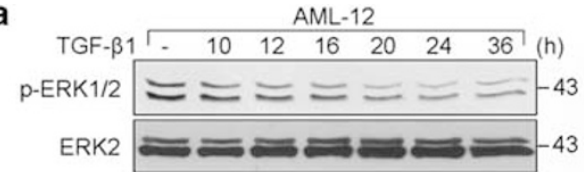

b
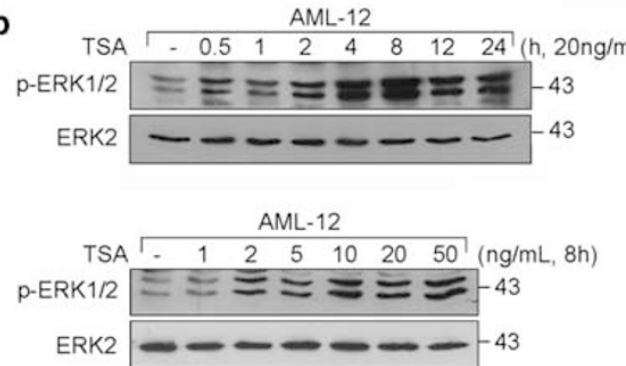

C

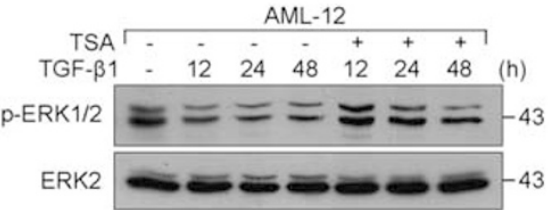

d

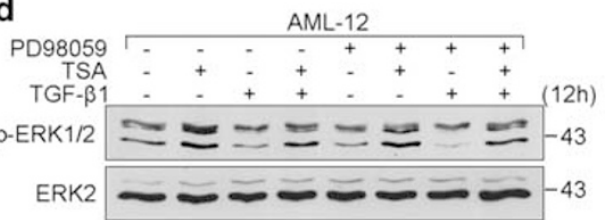

e

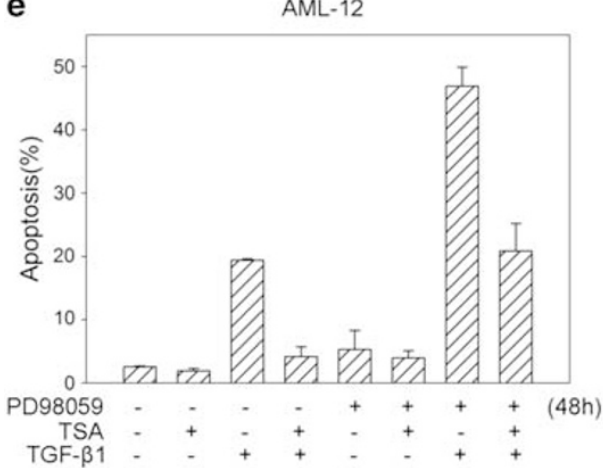

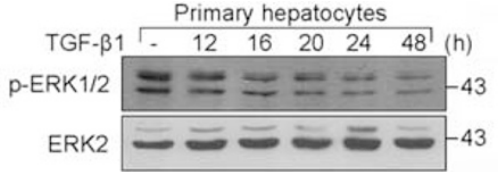
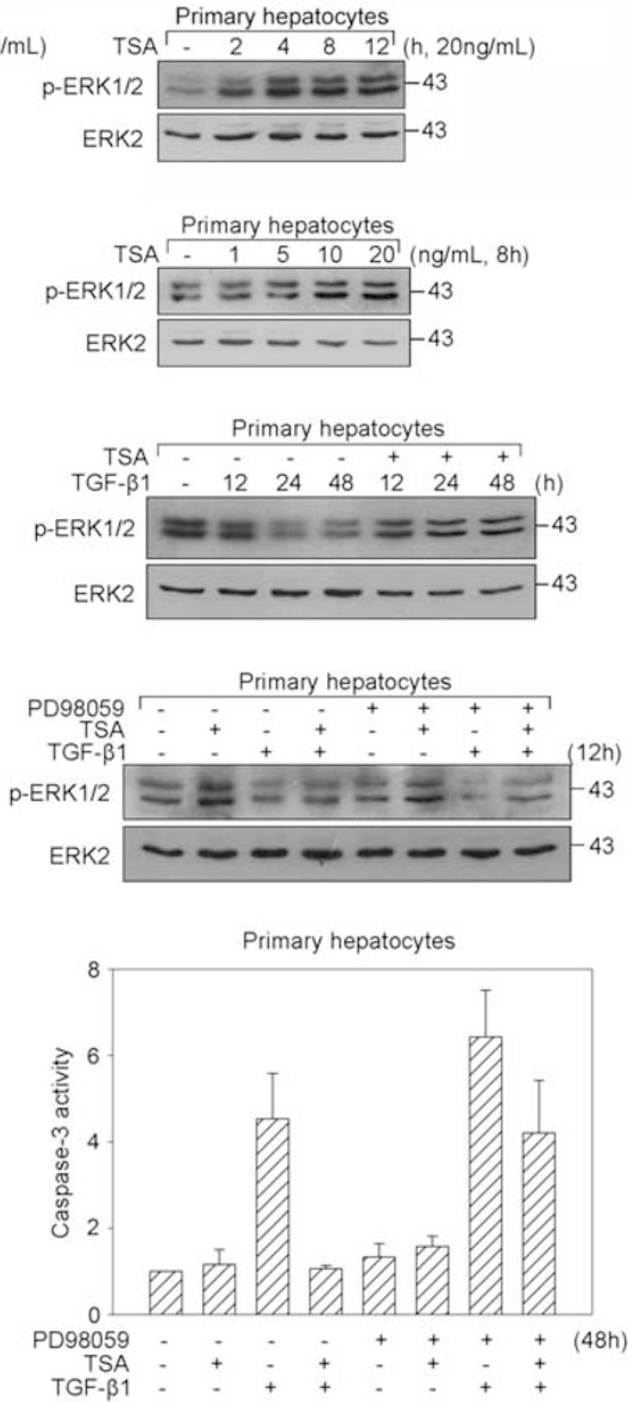

Figure 4 HDAC inhibitors abolish TGF- $\beta 1$-mediated inactivation of ERK $1 / 2$ to suppress the apoptosis in AML-12 (left panels) and primary hepatocytes (right panels). The effects of TGF- $\beta 1$ on $p$-ERK $1 / 2$ levels were examined by immunoblotting (a). TSA-mediated activation of ERK $1 / 2$ was examined by immunoblotting (b). The cells were treated with TSA $(20 \mathrm{ng} / \mathrm{ml})$ for the times indicated, in the presence or absence of TGF- $\beta 1$ or PD98059 $(20 \mu \mathrm{M})$. The p-ERK1/2 levels were determined by immunoblotting $(\mathbf{c}$ and $\mathbf{d})$ and cell apoptosis were determined by FACS in AML-12 cells (e, left panel) and by caspase-3 activity in primary hepatocytes (e, right panel). Data are presented as means \pm S.D. from at least three independent experiments

This suppression of TGF- $\beta 1$-induced apoptosis is a new function of HDAC inhibitors that has not been investigated and demonstrated in previous studies. In addition, our results demonstrate that three different HDAC inhibitors activate ERK1/2 to suppress TGF- $\beta 1$-induced apoptosis. Our results are consistent with the previous reports that the HDAC inhibitor valproic acid can activate $E R K 1 / 2$, resulting in suppression of serum starvation-induced apoptosis in human umbilical vein endothelial cells. ${ }^{38}$ Another HDAC inhibitor, apicidin, was also shown to activate ERK1/2. ${ }^{39}$ All of these
HDAC inhibitors are structurally unrelated: TSA is a hydroxamic acid compound, $\mathrm{NaBu}$ and valproic acid are short-chain fatty acids, whereas MS-275 is a benzamide and apicidin is a cyclic tetrapeptide. ${ }^{28}$ This indicates that activation of ERK1/2 is a common event induced by HDAC inhibitors and suggests that modulation of ERK $1 / 2$ activity is an important function of HDACs. By immunofluorescence staining and immune blotting, we found that HDAC inhibitors have no effect on the subcellular localisation and the expression levels of HDACs, suggesting that the regulation of subcellular localisation and 
a

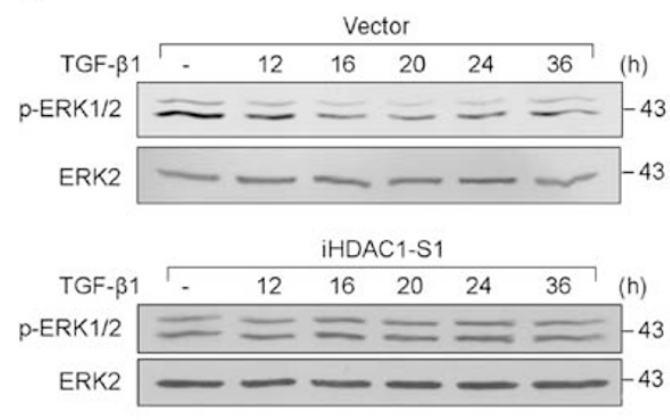

c

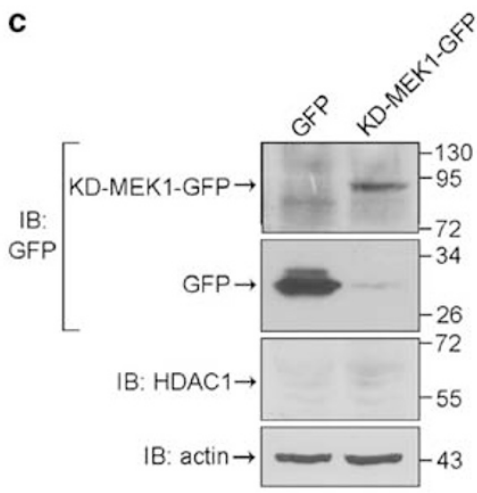

b

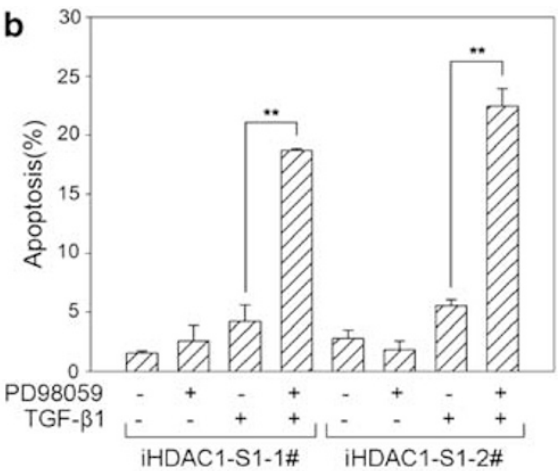

d

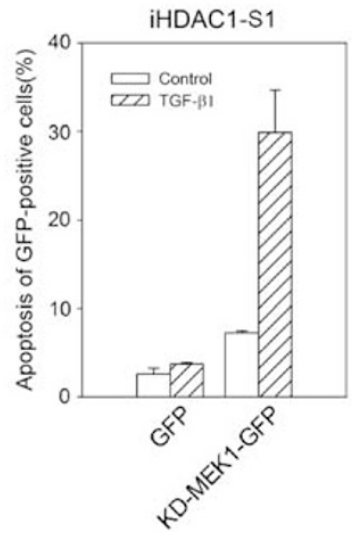

Figure 5 HDAC1 is involved in TGF- $\beta 1$-induced inactivation of ERK1/2 and cell apoptosis. The effect of HDAC1 siRNA on TGF- $\beta 1$-induced inactivation of ERK1/2 was examined by immunoblotting (a). iHDAC1 cells were treated with TGF- $\beta 1$ in the presence or absence of $20 \mu \mathrm{M}$ MEK1 inhibitor PD98059, and apoptosis was examined by FACS (b). The iHDAC1-S1-1\# cell clone was transiently transfected with GFP-tagged KD-MEK1 or the empty vector as examined by immunoblotting (c). The apoptotic response to TGF- $\beta 1$ in GFP-positive cells was examined by FACS (d). Data are the means \pm S.D. of at least three independent experiments

the expression of HDACs are not involved in the antiapoptotic function of HDAC inhibitors (data not shown).

Further study revealed that HDAC1 serves as a proapoptotic factor and HDAC2 serves as an antiapoptotic factor during TGF- $\beta 1$-induced apoptosis in AML-12 hepatocytes. These findings suggest that HDAC 1 and 2 possess reciprocal functions in the TGF- $\beta$ signalling pathway during apoptosis. Roles of HDACs in TGF- $\beta$-mediated biological events have begun to emerge in the past several years. It has been recently reported that HDAC2 functions as a key regulator for TGF- $\beta 1$-induced renal injury. ${ }^{40}$ HDAC4 reportedly acts as a regulator of TGF- $\beta 1$-induced myofibroblastic differentiation. ${ }^{41}$ HDAC6 has been shown to be required for TGF- $\beta 1$-induced epithelial-mesenchymal transition. ${ }^{42}$ HDAC4 and 5 were shown to be recruited by Smad3 to repress the transcription of Runx2 during TGF- $\beta 1$-mediated inhibition of osteoblast differentiation. ${ }^{43}$ To the best of our knowledge, it is not known whether HDACs are involved in the regulation of TGF- $\beta$-mediated apoptosis. This study provides the first insight into the roles and the potential mechanisms of HDAC1 and 2 in TGF- $\beta 1$-induced cell apoptosis.

ERK1/2 are important survival factors that promote cell growth and inhibit apoptosis. ${ }^{44,45}$ Our results showed that inactivation of ERK1/2 occurs during TGF- $\beta 1$-induced apoptosis. In iHDAC1 cells that do not undergo apoptosis by
TGF- $\beta 1$ treatment, $\mathrm{p}$-ERK1/2 levels remained high in response to TGF- $\beta 1$, whereas in iHDAC2 cells, the basal level of $p$-ERK $1 / 2$ was low, consistent with enhancement of spontaneous and TGF- $\beta 1$-induced apoptosis. These results confirm that the activation of ERK $1 / 2$ corresponds to the viability of AML-12 hepatocytes. Ramesh et al. ${ }^{46}$ reported that inhibition of ERK1/2 through the activation of MAPK phosphatase MKP2 is involved in the TGF- $\beta$-induced expression of the proapoptotic protein BIM and in apoptosis. This study demonstrates that reverse regulation of ERK $1 / 2$ is related to opposing roles of HDAC1 and 2 in apoptosis.

Lagger et al. ${ }^{47}$ reported that expression of HDAC2 and 3 was induced in HDAC1-deficient cells but could not compensate for the loss of HDAC1. In this study, the protein levels of HDAC2 and 1 were also reciprocally upregulated in iHDAC1 and 2 cells. However, it is not clear whether such increases have a respective role in these cells.

Because most HDAC inhibitors do not show specificity to different HDACs, the general or net effect of HDAC inhibitors cannot reflect the distinct roles of different HDACs. Our results demonstrate that HDAC1 and 2 have opposing roles in apoptosis. However, HDAC inhibitors, which can suppress both HDAC1 and 2, were found to inhibit apoptosis. These results indicate that suppression of HDAC1 but not HDAC2 can account for the inhibitory effect of HDAC 


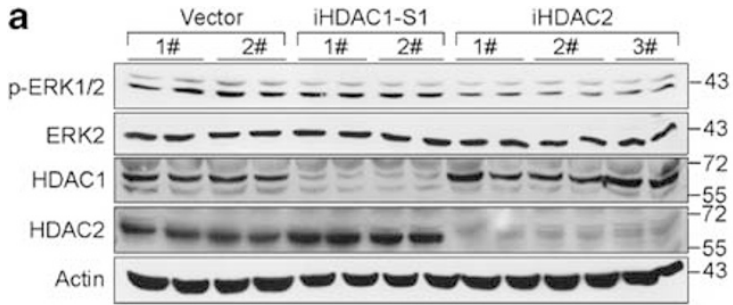

b
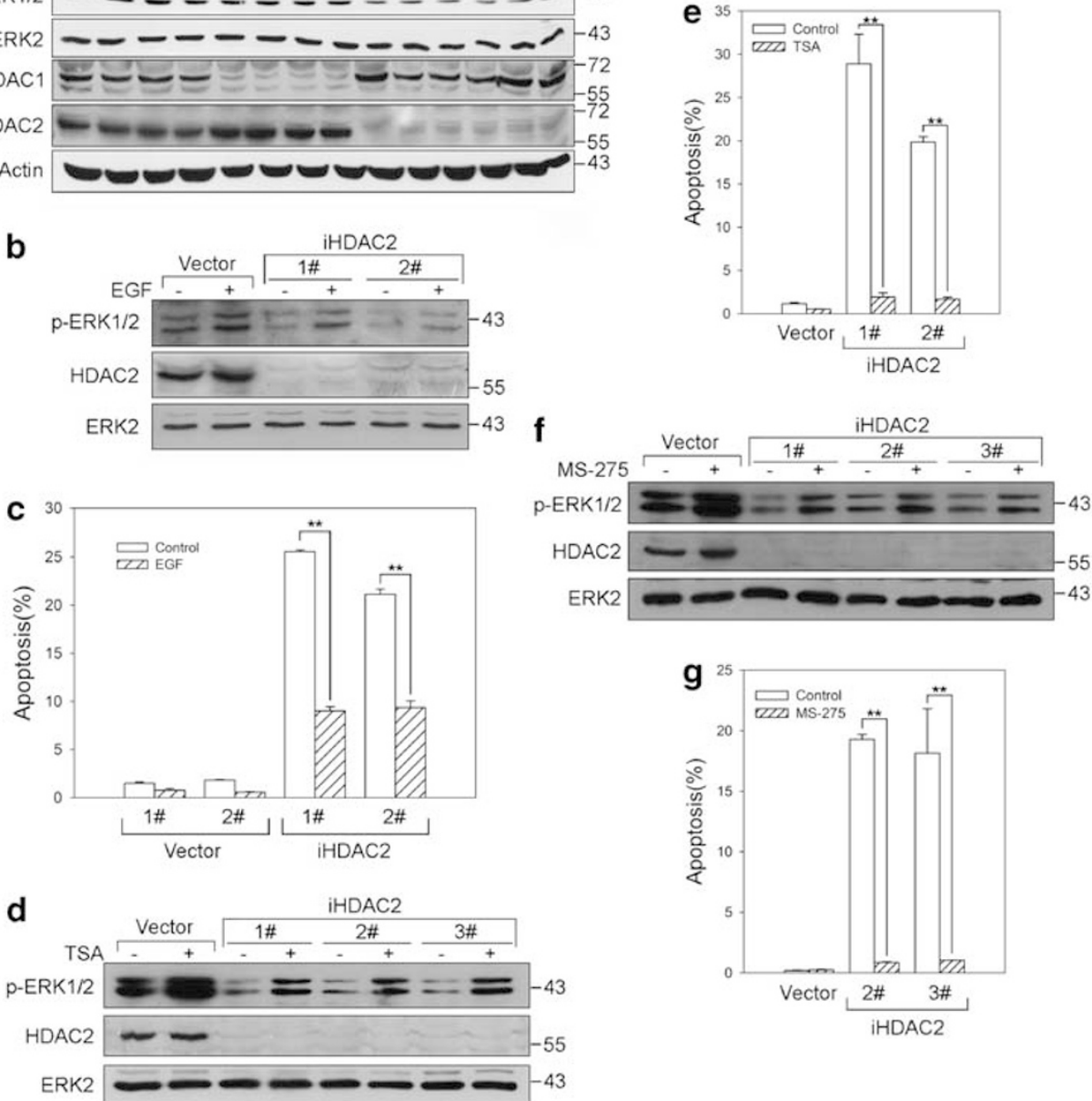

Figure 6 HDAC2 is important for maintaining ERK1/2 activation levels to keep cell survival. The basal levels of ERK1/2 activation were examined by immunoblotting in iHDAC1-S1, iHDAC2 and empty vector-transfected cells (a). The iHDAC2 cells were cultured in the presence or absence of $100 \mathrm{ng} / \mathrm{ml}$ EGF. The p-ERK1/2 levels were examined by immunoblotting $10 \mathrm{~min}$ after the treatment (b), and apoptosis were determined by FACS $72 \mathrm{~h}$ after the treatment (c). The iHDAC2 cells were treated with $20 \mathrm{ng} / \mathrm{ml}$ TSA (d, e) or $5 \mu \mathrm{M}$ MS-275 (f, $\mathbf{g})$. The $\mathrm{p}$-ERK $1 / 2$ levels were examined by immunoblotting $8 \mathrm{~h}$ after the treatment, apoptosis were determined by FACS $72 \mathrm{~h}$ after the treatment. The data represent the means \pm S.D. of at least three independent experiments

inhibitors during apoptosis. In addition, we also found that HDAC inhibitors suppressed spontaneous apoptosis in HDAC2-deficient cells, suggesting that the suppression of apoptosis by HDAC inhibitors is independent of HDAC2. As HDAC inhibitors has been reported to induce strong apoptosis in cancer cells, our finding that HDAC inhibitors can suppress apoptosis in non-cancer cells also suggests distinct physiological contexts between cancer and noncancer cells.

In conclusion, our data demonstrate that HDAC1 and 2 have opposing roles during TGF- $\beta 1$-induced apoptosis in AML-12 hepatocytes: the former functions as a proapoptotic factor, whereas the latter functions as a survival factor. These roles are dependent on opposing effects on ERK $1 / 2$ activation. This study provides insight into the role and potential mechanism of HDAC 1 and 2 on cell survival and apoptosis. As a summary of our study, a schematic illustration is shown in Figure 7.

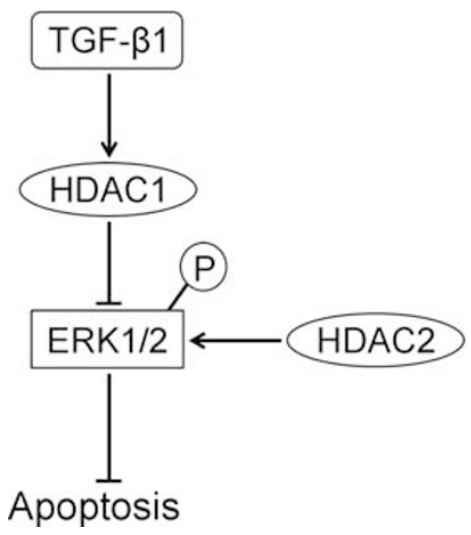

Figure 7 Schematic illustration. HDAC1 and 2 execute opposing functions in TGF- $\beta 1$-induced apoptosis by reverse regulation of ERK1/2. HDAC1 and 2 function as pro- and antiapoptotic factors, respectively. Co-operation between $\mathrm{HDAC1}$ and 2 regulates ERK $1 / 2$ activation levels and determines the death and survival of hepatocytes 


\section{Materials and Methods}

Materials. AML-12, MDCK and A549 cells were originally purchased from American Type Culture Collection (Manassas, VA, USA). TSA, NaBu, MS-275, Ac-DEVD-pNA (caspase-3 substrate) and human recombinant EGF were purchased from Sigma-Aldrich (St. Louis, MO, USA). PD98059 was from Calbiochem (La Jolla, CA, USA). Human recombinant TGF- $\beta 1$ was from Chemicon (Rosemont, IL, USA). Antibodies for $\beta$-actin, c-myc, HA, phosphoERK1/2, ERK2 and HRP-conjugated secondary antibodies were purchased from Santa Cruz Biotechnology (Santa Cruz, CA, USA).

Preparing HDAC1 and 2 anti-serum. The sequence differences between HDAC1 and 2 only exist at their C-terminals, so plasmids containing the C-termina sequences of HDAC1 and 2 in pGEX-4T-1 vector (GE Healthcare Bio-Sciences, Piscataway, NJ, USA) were constructed. The primer sequences used were as follows: 5'-GGAGAAGGTGGTCGCAAGAACTCTT-3' and $5^{\prime}$-CTGCAGACCTTG CTCAGGCC-3' for HDAC1, and $5^{\prime}$-CTGCAGACCTTGCTCAGGCC-3' and $5^{\prime}$-CTGCAGACCTTGCTCAGGCC-3' for HDAC2. The GST-tagged HDAC1 and 2 proteins were expressed and purified for immunisation of New Zealand white rabbits. The serum was collected after three immunisations.

Cell culture. Cell culture and transfection reagents were from Invitrogen (Carlsbad, CA, USA). AML-12 murine hepatocytes were cultured in a 1:1 mixture of Dulbecco's modified Eagle's medium (DMEM) and Ham's F12 containing 10\% feta bovine serum and supplied with insulin $(5 \mu \mathrm{g} / \mathrm{ml})$, transferrin $(5 \mu \mathrm{g} / \mathrm{ml})$, selenium $(5 \mu \mathrm{g} / \mathrm{ml})$, dexamethasone $(40 \mathrm{ng} / \mathrm{ml})$, penicillin $(100 \mathrm{units} / \mathrm{ml})$ and streptomycin $(100 \mu \mathrm{g} / \mathrm{ml})$. MDCK, A549 and 3T3-L1 cells were cultured in DMEM containing 10\% fetal bovine serum and supplied with penicillin $(100 \mathrm{U} / \mathrm{ml})$ and streptomycin $(100 \mu \mathrm{g} / \mathrm{ml})$. The cells were incubated at $37^{\circ} \mathrm{C}$ in a humidified atmosphere with $5 \%$ $\mathrm{CO}_{2}$. Experiments were performed when cells reached $40-60 \%$ confluence.

Isolation of mouse primary hepatocytes. Animal was housed in compliance with institutional guidelines. Mouse primary hepatocytes were isolated by a two-step in situ collagenase perfusion procedure, as described ${ }^{12}$ with minor modification. Livers from 4-week-old C57BL/6 mice (Shanghai Experimental Animal Center, Chinese Academy of Sciences) were perfused in situ through the portal vein with calcium- and magnesium-free Earl's basic salt solution (EBSS) for $10 \mathrm{~min}$ at a rate of $5 \mathrm{ml} / \mathrm{min}$, followed by EBSS containing $0.5 \mathrm{mg} / \mathrm{ml}$ of type IV collagenase for another $10 \mathrm{~min}$ at $37^{\circ} \mathrm{C}$. The hepatocytes were collected by centrifuging and seeded in DMEM/F12 medium, containing 15\% FBS.

Construction of plasmids. Dominant-negative HDAC1 mutant was generated through site mutation using PCR by changing histidine at position 141 to an alanine in the catalytic domain of the wild types and then cloning into pcDNA3.1 plasmid vector (Invitrogen). The wild-type HDAC1 and HA-tagged KD-MEK1 (K97A) were also subcloned into the pEGFPN3 plasmid vector (BD Biosciences, Franklin Lakes, NJ, USA). The target sequences for HDAC1 RNAi were 5'-GCAGATGCAGAGATTCAAT-3' (iHDAC1-S1) and 5'-GCAGCGTC TCTTTGAGAAC-3' (iHDAC1-S2). The target sequence for HDAC2 RNAi was $5^{\prime}$ GCATCAGGGTTCTGCTATG-3' (iHDAC2). These sequences were constructed into the PPGK-super plasmid vector.

Flow cytometry analysis of apoptosis. After the indicated treatment or transfection, cells were trypsinised and fixed with $2 \%$ paraformaldehyde for $15 \mathrm{~min}$ followed by incubation with $70 \%$ ethanol at $4^{\circ} \mathrm{C}$ for over $2 \mathrm{~h}$. Cells were then pelletted and washed with PBS containing $20 \mathrm{mM}$ EDTA. RNA was digested by incubating samples with RNase $A(1 \mathrm{mg} / \mathrm{ml})$ at $37^{\circ} \mathrm{C}$ for at least $1 \mathrm{~h}$. Cells were then stained with propidium iodide ( $\mathrm{Pl}$, final concentration: $30 \mu \mathrm{g} / \mathrm{ml}$ ). PI- and GFP-positive cells were detected by flow cytometry (Becton Dickinson FACS Calibur, BD Biosciences, San Jose, CA, USA). The cell apoptotic rate was measured by the percentage of the sub-G1 DNA quantity.

AO/EB staining. Cells were stained by AO $(2 \mu \mathrm{g} / \mathrm{ml})$ and EB ( $2 \mu \mathrm{g} / \mathrm{ml})$ (SigmaAldrich), and the fluorescence was visualised immediately using a fluorescence microscope. The live cells were stained uniformly green by $\mathrm{AO}$, and the fragmented or condensed nuclei of apoptotic cells were stained orange or red by EB.

DNA fragmentation assay. Cells were rinsed with PBS twice and incubated with $10 \mathrm{mM}$ Tris-Cl, pH 8.0, $25 \mathrm{mM}$ EDTA, pH 8.0, and $0.25 \%$ Triton X-100 on ice for $30 \mathrm{~min}$. After centrifugation at $12000 \times \mathrm{g}$ for $15 \mathrm{~min}$, the supernatant was incubated with RNAse at $37^{\circ} \mathrm{C}$ for $1 \mathrm{~h}$ and then with proteinase $\mathrm{K}$ at $56^{\circ} \mathrm{C}$ overnight. The DNA was extracted sequentially with phenol, phenol/chloroform (1:1), and chloroform. The DNA in the aqueous phase was precipitated and then separated by $1.5 \%$ agarose gel electrophoresis and visualised under transmitted UV light.

Preparation of cell lysates and immunoblotting. Cells were lysed in lysis buffer containing $50 \mathrm{mmol} / / \mathrm{HEPES}(\mathrm{pH} 7.4), 5 \mathrm{mmol} / \mathrm{I} \mathrm{EDTA}, 50 \mathrm{mmol} / / \mathrm{NaCl}$, $1 \%$ Triton X-100, $50 \mathrm{mmol} / \mathrm{l} \mathrm{NaF}, 10 \mathrm{mmol} / / \mathrm{Na}_{4} \mathrm{P}_{2} \mathrm{O}_{7} \cdot 10 \mathrm{H}_{2} \mathrm{O}, 5 \mu \mathrm{g} / \mathrm{ml}$ aprotinin, $5 \mu \mathrm{g} / \mathrm{ml}$ leupeptin, $1 \mathrm{mmol} / / \mathrm{Na}_{3} \mathrm{VO}_{4}$, and $1 \mathrm{mmol} / /$ phenylmethylsulfonyl fluoride. Proteins $(30 \mu \mathrm{g})$ were electrophoresed in SDS-polyacrylamide gels and transferred onto nitrocellulose membranes. The membranes were subsequently blocked with $5 \%$ skimmed milk and incubated with appropriate primary and second antibodies. Protein bands were visualised with super signal reagents.

Caspase-3 activity assay. Cells in 35-mm dishes were harvested by trypsin digestion and then were lysed in lysis buffer (containing 50 mmol// HEPES (pH7.4), $5 \mathrm{mmol} / / \mathrm{CHAPS}$ and $5 \mathrm{mmol} / \mathrm{l} \mathrm{DTT}$ ) on ice for $20 \mathrm{~min}$. After centrifuging, $50 \mu \mathrm{l}$ supernatant was mixed with $50 \mu \mathrm{l}$ assay buffer (containing $0.4 \mathrm{mmol} / \mathrm{l}$ Ac-DEVDpNA, $4 \mathrm{mmol} / /$ EDTA and $5 \mathrm{mmol} / \mathrm{I}$ DTT). Absorbance at $405 \mathrm{~nm}$ was calculated after the mixtures were incubated at $37^{\circ} \mathrm{C}$ for $8 \mathrm{~h}$. For statistic data of several experiments, the negative controls were set as 1.0 .

HDAC activity assay. Cells in $35-\mathrm{mm}$ dishes were lysed in the same lysis buffer as immunoblotting assay. After centrifuging, the supernatant was immunoprecipitated with $1 \mu \mathrm{l}$ of anti-serum of HDAC1 (or 2) and $20 \mu \mathrm{l}$ of slurry of $50 \%$ protein A Sepharose CL-4B beads (GE Healthcare, Piscataway, NJ, USA) on a rotator at $4{ }^{\circ} \mathrm{C}$ overnight. The immunoprecipitated beads were washed with lysis buffer and PBS three times, respectively. Then HDAC1 or 2 activity was examined by HDAC assay kit from Upstate (Millipore, Billerica, MA, USA). Absorbance at $405 \mathrm{~nm}$ was calculated and for statistic data of several experiments, the negative controls were set as 1.0

Cell transfection. Cells in $35-\mathrm{mm}$ dishes were transfected with $2 \mu \mathrm{g}$ of plasmid using the Lipofectamine transfection reagent (Invitrogen) according to the manufacturer's instruction. For transient transfection, expression of the indicated plasmids was examined $48 \mathrm{~h}$ after transfection. For selecting the stable cell clones, G418 $(800 \mu \mathrm{g} / \mathrm{ml})$ was added $48 \mathrm{~h}$ after the transfection.

Confocal analysis. Cells stably transfected with GFP and HDAC1-GFP were grown on glass slides. When cells reached confluence, the slides were washed with PBS and fixed in 4\% paraformaldehyde and permeabilised in $0.1 \%$ Triton X-100. The nuclei were stained with DAPI. The fluorescence was visualised using confocal fluorescence microscopy (Leica, Mannheim, Germany).

Statistical analysis. Quantitative data were expressed as means \pm S.D. or S.E. for at least three independent experiments. Statistical significance was determined by Student's $t$-test. Differences were considered significant at $P<0.05$. ${ }^{\star} P<0.05 ;{ }^{* \star} P<0.001$

\section{Conflict of interest}

The authors declare no conflict of interest.

Acknowledgements. We are grateful to Dr. T Kouzarides for the plasmids of wild-type human HDAC1 and mouse HDAC2, Dr. NG Ahn for the plasmid encoding the kinase-dead form of human MEK1 (K97A), and Dr. Y Wang and Dr. K Liao for the plasmids of pPGK-super vector and the 3T3-L1 cell line, respectively. We also thank Dr. H-H Chen, G-W Shu, J Shi, X-D Wang, L Zhang, X-W Yuan and Y-N Tang for technical supports and many helpful discussions. This work was supported by The Natural Science Foundation of China (30730023, 30721065 and 30623003), the National Basic Research Program of China (2007CB947900) and the Shanghai Science Committee 088014199.

1. Oberhammer FA, Pavelka M, Sharma S, Tiefenbacher R, Purchio AF, Bursch W et al. Induction of apoptosis in cultured hepatocytes and in regressing liver by transforming growth factor beta 1. Proc Natl Acad Sci USA 1992; 89: 5408-5412. 
2. Lin JK, Chou CK. In vitro apoptosis in the human hepatoma cell line induced by transforming growth factor beta 1. Cancer Res 1992; 52: 385-388.

3. Fan G, Ma X, Kren B, Steer C. The retinoblastoma gene product inhibits TGF-beta1 induced apoptosis in primary rat hepatocytes and human $\mathrm{HuH}-7$ hepatoma cells. Oncogene 1996; 12: 1909-1919.

4. Bayly A, Roberts R, Dive C. Suppression of liver cell apoptosis in vitro by the non-genotoxic hepatocarcinogen and peroxisome proliferator nafenopin. J Cell Biol 1994; 125: 197-203.

5. Schuster N, Krieglstein K. Mechanisms of TGF-beta-mediated apoptosis. Cell Tissue Res 2002; 307: 1-14.

6. Liao JH, Chen JS, Chai MQ, Zhao S, Song JG. The involvement of p38 MAPK in transforming growth factor beta1-induced apoptosis in murine hepatocytes. Cell Res 2001; 11: 89-94.

7. Lee CG, Kang HR, Homer RJ, Chupp G, Elias JA. Transgenic modeling of transforming growth factor-beta(1): role of apoptosis in fibrosis and alveolar remodeling. Proc Am Thorac Soc 2006; 3: 418-423.

8. Aoki CA, Borchers AT, Li M, Flavell RA, Bowlus CL, Ansari AA et al. Transforming growth factor beta (TGF-beta) and autoimmunity. Autoimmun Rev 2005; 4: 450-459.

9. Wrzesinski SH, Wan YY, Flavell RA. Transforming growth factor-beta and the immune response: implications for anticancer therapy. Clin Cancer Res 2007; 13 (18 Part 1): 5262-5270.

10. Owens DM, Keyse SM. Differential regulation of MAP kinase signalling by dual-specificity protein phosphatases. Oncogene 2007; 26: 3203

11. Park HJ, Kim B-C, Kim SJ, Choi KS. Role of MAP kinases and their cross-talk in TGF-beta1-induced apoptosis in FaO rat hepatoma cell line. Hepatology 2002; 35: 1360-1371.

12. Godoy P, Hengstler JG, Ilkavets I, Meyer C, Bachmann A, Müller A et al. Extracellular matrix modulates sensitivity of hepatocytes to fibroblastoid dedifferentiation and transforming growth factor beta-induced apoptosis. Hepatology 2009; 49: 2031-2043.

13. Dixon M, Agius L, Yeaman SJ, Day CP. Inhibition of rat hepatocyte proliferation by transforming growth factor beta and glucagon is associated with inhibition of ERK2 and p70 S6 kinase. Hepatology 1999; 29: 1418-1424.

14. Giehl K, Seidel B, Gierschik P, Adler G, Menke A. TGFbeta1 represses proliferation of pancreatic carcinoma cells which correlates with Smad4-independent inhibition of ERK activation. Oncogene 2000; 19: 4531-4541.

15. Chin BY, Petrache I, Choi AMK, Choi ME. Transforming growth factor beta1 rescues serum deprivation-induced apoptosis via the mitogen-activated protein kinase (MAPK) pathway in macrophages. J Biol Chem 1999; 274: 11362-11368.

16. Ghayor C, Rey A, Caverzasio J. Prostaglandin-dependent activation of ERK mediates cell proliferation induced by transforming growth factor beta in mouse osteoblastic cells. Bone 2005; 36: 93-100.

17. Chen G, Khalil N. TGF-beta1 increases proliferation of airway smooth muscle cells by phosphorylation of map kinases. Respir Res 2006; 7: 2.

18. Tian YC, Chen YC, Chang CT, Hung CC, Wu MS, Phillips A et al. Epidermal growth factor and transforming growth factor-beta1 enhance HK-2 cell migration through a synergistic increase of matrix metalloproteinase and sustained activation of ERK signaling pathway. Exp Cell Res 2007; 313: 2367-2377.

19. Giehl K, Imamichi Y, Menke A. Smad4-independent TGF-beta signaling in tumor cell migration. Cells Tissues Organs 2007; 185: 123-130.

20. Leloup L, Daury L, Mazères G, Cottin P, Brustis J-J. Involvement of the ERK/MAP kinase signalling pathway in milli-calpain activation and myogenic cell migration. Int $\mathrm{J}$ Biochem Cell Biol 2007; 39: 1177-1189.

21. Ellenrieder V, Hendler SF, Boeck W, Seufferlein T, Menke A, Ruhland C et al. Transforming growth factor beta1 treatment leads to an epithelial-mesenchymal transdifferentiation of pancreatic cancer cells requiring extracellular signal-regulated kinase 2 activation. Cancer Res 2001; 61: 4222-4228.

22. Xie L, Law BK, Chytil A, Brown KA, Aakre M, Moses HL. Activation of the Erk pathway is required for TGF-beta1-induced EMT in vitro. Neoplasia 2004; 6: 603-610.

23. Haberland M, Montgomery RL, Olson EN. The many roles of histone deacetylases in development and physiology: implications for disease and therapy. Nat Rev Genet 2009; 10: $32-42$.

24. Montgomery RL, Davis CA, Potthoff MJ, Haberland M, Fielitz J, Qi X et al. Histone deacetylases 1 and 2 redundantly regulate cardiac morphogenesis, growth, and contractility. Genes Dev 2007; 21: 1790-1802.

25. Humphrey GW, Wang Y-H, Hirai T, Padmanabhan R, Panchision DM, Newell LF et al. Complementary roles for histone deacetylases 1,2 , and 3 in differentiation of pluripotent stem cells. Differentiation 2007; 76: 348-356.

26. Senese S, Zaragoza K, Minardi S, Muradore I, Ronzoni S, Passafaro A et al. Role for histone deacetylase 1 in human tumor cell proliferation. Mol Cell Biol 2007; 27: 4784-4795.

27. Huang BH, Laban M, Leung CH-W, Lee L, Lee CK, Salto-Tellez M et al. Inhibition of histone deacetylase 2 increases apoptosis and p21Cip1/WAF1 expression, independent of histone deacetylase 1. Cell Death Differ 2005; 12: 395-404.

28. Bolden JE, Peart MJ, Johnstone RW. Anticancer activities of histone deacetylase inhibitors. Nat Rev Drug Discov 2006; 5: 769-784.

29. Minucci S, Pelicci PG. Histone deacetylase inhibitors and the promise of epigenetic (and more) treatments for cancer. Nat Rev Cancer 2006; 6: 38-51.

30. Carew JS, Giles FJ, Nawrocki ST. Histone deacetylase inhibitors: mechanisms of cell death and promise in combination cancer therapy. Cancer Lett 2008; 269: 7-17.

31. Wu JC, Merlino G, Fausto N. Establishment and characterization of differentiated, nontransformed hepatocyte cell lines derived from mice transgenic for transforming growth factor alpha. Proc Natl Acad Sci USA 1994; 91: 674-678.

32. Yang $Y$, Pan X, Lei W, Wang J, Song J. Transforming growth factor-beta1 induces epithelial-to-mesenchymal transition and apoptosis via a cell cycle-dependent mechanism. Oncogene 2006; 25: 7235-7244.

33. Yang Y, Pan X, Lei W, Wang J, Shi J, Li F et al. Regulation of transforming growth factorbeta1-induced apoptosis and epithelial-to-mesenchymal transition by protein kinase $A$ and signal transducers and activators of transcription 3. Cancer Res 2006; 66: 8617-8624.

34. Hu E, Dul E, Sung CM, Chen Z, Kirkpatrick R, Zhang GF et al. Identification of novel isoform-selective inhibitors within class I histone deacetylases. J Pharmacol Exp Ther 2003; 307: 720-728.

35. Khan N, Jeffers M, Kumar S, Hackett C, Boldog F, Khramtsov N et al. Determination of the class and isoform selectivity of small-molecule histone deacetylase inhibitors. Biochem J 2003; 409: 581-589.

36. Hassig CA, Fleischer TC, Billin AN, Schreiber SL, Ayer DE. Histone deacetylase activity is required for full transcriptional repression by $\mathrm{mSin} 3 \mathrm{~A}$. Cell 1997; 89: 341-347.

37. Grozinger CM, Hassig CA, Schreiber SL. Three proteins define a class of human histone deacetylases related to yeast Hda1p. Proc Natl Acad Sci USA 1999; 96: 4868-4873.

38. Michaelis M, Suhan T, Michaelis UR, Beek K, Rothweiler F, Tausch L et al. Valproic acid induces extracellular signal-regulated kinase $1 / 2$ activation and inhibits apoptosis in endothelial cells. Cell Death Differ 2006; 13: 446-453.

39. Park H, Im JY, Kim J, Choi WS, Kim HS. Effects of apicidin, a histone deacetylase inhibitor, on the regulation of apoptosis in $\mathrm{H}$-ras-transformed breast epithelial cells. Int $\mathrm{J} \mathrm{Mol} \mathrm{Med}$ 2008; 21: 325-333.

40. Noh H, Oh EY, Seo JY, Yu MR, Kim YO, Ha H et al. Histone deacetylase-2 is a key regulator of diabetes- and transforming growth factor-beta1-induced renal injury. $A m \mathrm{~J}$ Physiol Renal Physiol 2009; 297: F729-F739.

41. Glenissona W, Castronovoa V, Waltregny D. Histone deacetylase 4 is required for TGFbeta1-induced myofibroblastic differentiation. Biochim Biophys Acta 2007; 1773: 1572-1582.

42. Shan B, Yao TP, Nguyen HT, Zhuo Y, Levy DR, Klingsberg RC et al. Requirement of HDAC6 for transforming growth factor-beta1-induced epithelial-mesenchymal transition. J Biol Chem 2008; 283: 21065-21073.

43. Kang JS, Alliston T, Delston R, Derynck R. Repression of Runx2 function by TGF-beta through recruitment of class II histone deacetylases by Smad3. EMBO J 2002; 24: 2543-2555.

44. Meloche S, Pouysségur J. The ERK1/2 mitogen-activated protein kinase pathway as a master regulator of the G1- to S-phase transition. Oncogene 2007; 26: 3227-3239.

45. Balmanno K, Cook SJ. Tumour cell survival signalling by the ERK1/2 pathway. Cell Death Differ 2009; 16: 368-377.

46. Ramesh S, Qi X-J, Wildey GM, Robinson J, Molkentin J, Letterio J et al. TGF beta-mediated BIM expression and apoptosis are regulated through SMAD3-dependent expression of the MAPK phosphatase MKP2. EMBO Rep 2008; 9: 990-997.

47. Lagger G, O'Carroll D, Rembold M, Khier H, Tischler J, Weitzer G et al. Essential function of histone deacetylase 1 in proliferation control and CDK inhibitor repression. EMBO J 2002; 21: 2672-2681.
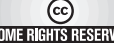

Cell Death and Disease is an open-access journal published by Nature Publishing Group. This article is licensed under a Creative Commons Attribution-Noncommercial-Share Alike 3.0 License. To view a copy of this license, visit http:/l creativecommons.org/licenses/by-nc-sa/3.0/

\section{Supplementary Information accompanies the paper on Cell Death and Disease website (http://www.nature.com/cddis)}

